\title{
Unilateral versus bilateral hilar stents for the treatment of cholangiocarcinoma: a multicenter international study
}

\author{
Judith Stauba, Ali Siddiqui ${ }^{b}$, Megan Murphyb, Robert Lamb , Meet Parikh ${ }^{b}$, Douglas Pleskow', \\ Georgios Papachristou ${ }^{d}$, Reem Sharaiha ${ }^{e}$, Usama Iqbal', David Loren ${ }^{b}$, Thomas Kowalski ${ }^{b}$, Arish Noor ${ }^{b}$, \\ Tayebah Mumtaz ${ }^{g}$, Ichiro Yasudah , Samuel Thomas ${ }^{\mathrm{a}}$, Abdul Hsaeeb ${ }^{\mathrm{a}}$, Jennifer Herrick ${ }^{\mathrm{a}}$, Tom Greene ${ }^{\mathrm{a}}$, \\ Douglas G. Adler ${ }^{\mathrm{a}}$
}

University of Utah, Salt Lake City, USA; Thomas Jefferson University Hospital, Philadelphia, USA; Beth Israel Deaconess Medical Center, Boston, USA; University of Pittsburgh, USA; Weill Cornell Medical College, New York, USA; Drexel University, Philadelphia, USA; Geisinger Commonwealth School of Medicine, Scranton, Pennsylvania; Teikyo University Mizonokuchi Hospital, Japan

\section{Abstract}

Background Endoscopic placement of hilar stents is an accepted palliative therapy for patients with advanced, unresectable cholangiocarcinoma. However, whether unilateral versus bilateral stent placement provides optimal relief continues to be a subject of debate. The aim of this study was to compare the technical and clinical outcomes in patients with inoperable cholangiocarcinoma who received unilateral or bilateral self-expanding metal stents (SEMS).

Methods We conducted a multicenter, international retrospective study of 187 patients with cholangiocarcinoma who received unilateral or bilateral SEMS. Outcomes included, but were not limited to, technical success, clinical success, adverse events, stent occlusion, and survival time. Results were further stratified based on the Bismuth classification.

Results Fifty patients received unilateral stents and 137 patients received bilateral stents. All patients achieved technical success. The clinical success rates were $86 \%$ for unilateral stents and $82.5 \%$ for bilateral stents $(\mathrm{P}>0.99)$. Clinical success was not statistically different for either group when stratified by the Bismuth classification $(\mathrm{P}=0.62$ and $\mathrm{P}=0.72$ respectively). There were significantly more adverse events in the bilateral stents group $(11.7 \%$ vs. $0 \%, \mathrm{P}=0.007)$. There was no greater risk of stent occlusion when bilateral stents were used (unadjusted $\mathrm{P}=0.71$, adjusted $\mathrm{P}=0.81$ ). There was a greater risk of death for patients who received bilateral SEMS (hazard ratio 1.78, 95\% confidence interval 1.09-2.89; $\mathrm{P}=0.02$ ).

Conclusions Unilateral and bilateral drainage had similar technical and clinical success rates. However, bilateral stents had a higher risk of death and more adverse events. Therefore, unilateral SEMS placement is sufficient for relief of biliary obstruction secondary to cholangiocarcinoma.

Keywords Cholangiocarcinoma, self-expanding metal stent, hilar, unilateral, bilateral

Ann Gastroenterol 2020; 33 (2): 1-8

\begin{abstract}
Department of Gastroenterology, a University of Utah, Salt Lake City, UT (Judith Staub, Samuel Thomas, Abdul Hsaeeb, Jennifer Herrick, Tom Greene, Douglas G. Adler); ${ }^{\text {b}}$ Thomas Jefferson University Hospital, Philadelphia, PA (Ali Siddiqui, Megan Murphy, Robert Lam, Meet Parikh, David Loren, Thomas Kowalski, Arish Noor); ${ }^{\mathrm{c} B e t h}$ Israel Deaconess Medical Center, Boston, MA (Douglas Pleskow); 'University of Pittsburgh, Pittsburgh, PA (Georgios Papachristou); ${ }^{\text {WWill Cornell }}$ Medical College, New York City, NY (Reem Sharaiha); ${ }^{\mathrm{f}}$ Drexel

University, Philadelphia, PA (Usama Iqbal); ${ }^{\mathrm{g}}$ Geisinger Commonwealth School of Medicine, Scranton, Pennsylvania (Tayebah Mumtaz);

'Teikyo University Mizonokuchi Hospital, Japan (Ichiro Yasuda)

Conflict of Interest: None
\end{abstract}

Received 6 September 2019; accepted 15 November 2019; published online 12 February 2020

DOI: https://doi.org/10.20524/aog.2020.0451
Correspondence to: Douglas G. Adler MD, FACG, AGAF, FASGE, Professor of Medicine, Director of Therapeutic Endoscopy, Director, GI Fellowship Program, Gastroenterology and Hepatology, University of Utah School of Medicine, Huntsman Cancer Center, 30N 1900E 4R118, Salt Lake City, Utah 84132, USA, e-mail: douglas.adler@hsc.utah.edu

\section{Introduction}

Cholangiocarcinoma is a rare and aggressive malignancy that often leads to the development of obstructive jaundice, a decreased quality of life and an increased risk of cholangitis. Surgical bile duct resection or hepatectomy is reserved for patients who present at an early stage, but hilar cholangiocarcinoma is often detected at an advanced stage when patients are no longer surgical candidates [1]. Endoscopic intervention with biliary 
stenting is a well-established palliative therapy for patients who have advanced cholangiocarcinoma with obstructive jaundice; however, the optimal drainage technique remains controversial. Prior studies have demonstrated that metal stents are superior to plastic stents with regard to survival, drainage adequacy and cost effectiveness [2,3]. However, there is an ongoing debate as regards the outcomes of unilateral versus bilateral stent placement for cholangiocarcinoma. The aim of this retrospective study was to investigate and compare the clinical outcomes in patients with inoperable hilar cholangiocarcinoma who received unilateral or bilateral self-expanding metal stents (SEMS).

\section{Patients and methods}

We performed a multicenter, retrospective review of patients with hilar cholangiocarcinoma who underwent endoscopic retrograde cholangiopancreatography (ERCP) with uncovered SEMs between 2006 and 2015 at 8 centers in the US and Japan. The 8 academic centers that participated were the University of Utah, Jefferson University School of Medicine, the University of Pittsburgh, Drexel University, Weill Cornell Medical College, Beth Israel Deaconess Medical Center, Geisinger Commonwealth School of Medicine, and Teikyo University Mizonokichi Hospital in Japan. Patient data were allocated into 2 groups: those who received a unilateral SEMS in a dilated segment of either the right or the left intrahepatic duct, and those who received bilateral SEMSs in both those locations. Medical records, endoscopy reports, laboratory results, radiologic studies, telephone records and other records were reviewed for all patients included in the study.

Compiled data included, but were not limited to, patient demographics, indication for procedure, pre- and postprocedure bilirubin levels, and adverse events. Data were also further subdivided based on the Bismuth classification. Type I tumors are distal to the hepatic duct confluence (HDC), Type II tumors extend to and involve the HDC, Type III involve the HDC and either the right hepatic duct or the left hepatic duct, and Type IV involve the HDC as well as the bilateral proximal hepatic ducts and up to the segmental bile ducts [4].

Outcome data included technical and clinical success of the procedure, survival time following procedure and time to stent occlusion. Technical success was defined as passage of unilateral or bilateral metal stents across the stricture as intended, successful deployment of the stents, and visualized flow of contrast medium and/or bile through stents. Clinical success was defined as any decrease in bilirubin 2 weeks post-procedurally and further analyzed by percentage bilirubin reduction. This study was approved by an institutional review board at all centers.

\section{Statistical analysis}

Student's $t$-test and the Kruskal-Wallis test were used to compare the means and medians of the continuous variables in the unilateral and bilateral stent groups. The chi-square test and
Fisher's exact test were used to compare the distributions of the categorical variables in the 2 groups. A univariate and multivariate linear regression analysis was performed to determine whether bilirubin levels were statistically significantly different in the unilateral and bilateral stent groups. Hazard ratios (HR) were calculated from the Cox proportional hazards model to determine whether unilateral or bilateral stenting was associated with time to death and time to stent occlusion in weeks. A comparison of cause-specific hazards for stent occlusion was performed with death censored. Patients who died before stent occlusion occurred were excluded from the analyses of time to death and time to composite stent occlusion or death. Observations were considered right censored if the event of interest did not happen within the observation period. All multivariate regression and hazards models were adjusted for age, sex and Bismuth classification. Kaplan-Meier plots were created of the time to event data overall and stratified by Bismuth classification.

\section{Results}

\section{Demographics}

A total of 187 patients were included in this study, of whom $42.8 \%$ were female. Of the 187 patients, 50 received unilateral hilar stents $(50 / 187,26.7 \%)$ and 137 received bilateral hilar stents $(137 / 187,73.3 \%)$. The mean age of all patients was $72.4 \pm 9.7$ years: $73.1 \pm 10.6$ years for patents who received unilateral SEMS, and 72.1 \pm 9.3 years for those who received bilateral SEMS (Table 1).

The primary indication for ERCP was jaundice in $162 / 187$ patients (86.6\%). Other indications included abnormal imaging suggestive of a mass lesion in 15 patients $(15 / 187,8.0 \%)$ and cholangitis in 10 patients $(10 / 187,5.3 \%)$. There was no significant difference between the 2 groups in the sex, age, or procedural indication $(\mathrm{P}=0.14, \mathrm{P}=0.56$, and $\mathrm{P}=0.06$ respectively).

\section{Bismuth classification}

Of patients who received unilateral stenting, 16 were Bismuth Type I (16/50, 32.0\%), 20 were Type II (20/50, 40.0\%), 6 were Type III $(6 / 50,12 \%)$, and 8 were Type IV $(8 / 50,16.0 \%)$. Among patients who received bilateral stents, 30 were Bismuth Type I (30/137, 21.9\%), 46 were Type II (46/137, 33.6\%), 16 were Type III $(16 / 137,11.7 \%)$, and 45 were type IV (45/137, $32.8 \%$ ) (Table 1). The stents used included the Boston Scientific WallFlex $^{\mathrm{TM}}$ uncovered SEMS or the Cook Zilver ${ }^{\circledast}$ uncovered SEMS. In patients who underwent bilateral stent placement, they were either placed side by side or had a stent-in-stent deployment.

\section{Overall technical and clinical success}

Technical success was achieved in all 187 (100\%) patients examined in the study. The number of patients who achieved 
Table 1 Descriptive table by stent type

\begin{tabular}{|c|c|c|c|c|}
\hline \multirow[t]{2}{*}{ Characteristics } & Total & Unilateral & Bilateral & \multirow[t]{2}{*}{$\mathrm{P}$-value } \\
\hline & $(\mathrm{N}=187)$ & $(\mathrm{N}=50)$ & $(\mathrm{N}=137)$ & \\
\hline Female & $80(42.8)$ & $17(34.0)$ & $63(46.0)$ & 0.14 \\
\hline Age (mean \pm SD) & $72.4 \pm 9.7$ & $73.1 \pm 10.6$ & $72.1 \pm 9.3$ & 0.56 \\
\hline \multicolumn{5}{|l|}{ Bismuth classification } \\
\hline I & $46(24.6)$ & $16(32.0)$ & $30(21.9)$ & \multirow[t]{4}{*}{0.13} \\
\hline II & $66(35.3)$ & $20(40.0)$ & $46(33.6)$ & \\
\hline III & $22(11.8)$ & $6(12.0)$ & $16(11.7)$ & \\
\hline IV & $53(28.3)$ & $8(16.0)$ & $45(32.8)$ & \\
\hline \multicolumn{5}{|l|}{ Stent manufacturer } \\
\hline Boston Scientific & $141(75.4)$ & $19(38.0)$ & $122(89.1)$ & \multirow[t]{4}{*}{$<0.001$} \\
\hline Cook & $36(19.3)$ & $21(42.0)$ & $15(10.9)$ & \\
\hline Taewoong & $8(4.3)$ & $8(16.0)$ & $0(0.0)$ & \\
\hline Other & $2(1.1)$ & $2(4.0)$ & $0(0.0)$ & \\
\hline \multicolumn{5}{|l|}{ Procedure indications } \\
\hline Jaundice & $161(86.6)$ & $41(82.0)$ & $120(88.2)$ & \multirow[t]{3}{*}{0.06} \\
\hline Abnormal imaging & $15(8.1)$ & $3(6.0)$ & $12(8.8)$ & \\
\hline Cholangitis & $10(5.4)$ & $6(12.0)$ & $4(2.9)$ & \\
\hline \multicolumn{5}{|l|}{ Pancreatic duct stent placement } \\
\hline Yes & $18(9.6)$ & $12(24.0)$ & $6(4.4)$ & $<0.001$ \\
\hline Bile duct size above stricture (median [Q1, Q3]) & $8.0(8.0,11.0)$ & $8.5(7.0,11.0)$ & $8.0(8.0,10.0)$ & 0.84 \\
\hline
\end{tabular}

clinical success, defined as a decrease in bilirubin following ERCP at 2-4 weeks, was not statistically different between the 2 groups: $43 / 50$ (86\%) patients in the unilateral stents group had a decrease in bilirubin compared to $115 / 137$ (82.5\%) in the bilateral stents group $(\mathrm{P}>0.99)$ (Table 2$)$.

\section{Clinical success by bilirubin reduction}

The median bilirubin levels before stent placement were $4.8 \mathrm{mg} / \mathrm{dL}$ in the unilateral stent group and $6.9 \mathrm{mg} / \mathrm{dL}$ in the bilateral group $(\mathrm{P}=0.02)$. The median bilirubin level 2-4 weeks after placement was significantly lower in the unilateral group than in the bilateral group $(1.4 \mathrm{vs} .3 .1 \mathrm{mg} / \mathrm{dL}$, respectively; $\mathrm{P}=0.002$ ). However, the median decrease in bilirubin after SEMS placement did not differ significantly, being $2.7 \mathrm{mg} / \mathrm{dL}$ for unilateral stents and $2.4 \mathrm{mg} / \mathrm{dL}$ for bilateral stents $(\mathrm{P}=0.85)$ (Table 2). There was no difference in bilirubin reduction between the unilateral and bilateral stent groups when patients were stratified according to whether their decrease in bilirubin was $\geq 75 \%$, $>50$ to $<75 \%$, or $\leq 50 \%$ from the level before stent placement $(\mathrm{P}=0.06)$ (Table 2). On multivariate analysis. adjusting for age, sex, and Bismuth classification, the average bilirubin reduction was not statistically different $(0.49,95 \%$ confidence interval [CI] -1.17 to $2.14 ; \mathrm{P}=0.56$ ) (Supplementary Table 1).

\section{Clinical success by Bismuth classification}

The 2 groups were further analyzed by clinical success in relation to their Bismuth Classification.

For unilateral stents, there was no significant difference in clinical success when analyzed by Bismuth class (13/16, 81.3\% Type I; 18/20, 90\% Type II; 5/6, 83.3\% Type III; 7/8, $87.5 \%$ Type IV; $\mathrm{P}=0.95$ ) (Supplementary Table 2). The median decrease in bilirubin after stent placement was $3.4 \mathrm{mg} / \mathrm{dL}$ (interquartile range [IQR] 0.6-5.4) for Type I, $2.4 \mathrm{mg} / \mathrm{dL}$ (IQR 1.2-4.2) for Type II, $2.9 \mathrm{mg} / \mathrm{dL}$ (IQR 0.5-4.7) for Type III, and $2.1 \mathrm{mg} / \mathrm{dL}$ (IQR 0.7-5.3) for Type IV; these values did not differ significantly $(\mathrm{P}=0.92)$. Further, when patients were stratified into those with a bilirubin reduction of $\geq 75 \%,>50$ to $<75 \%$, or $\leq 50 \%, 2-4$ weeks following stent placement, there was no statistical difference between Bismuth classifications $(\mathrm{P}=0.62)$ (Supplementary Table 2).

Similarly, for patients who received bilateral stents there was no difference in the number of patients who had a decrease in bilirubin following stent placement when stratified by Bismuth classification (24/30, 80\% Type I; 40/46, 87\% Type II; 14/16, 87.5\% Type III; 37/45, 82.2\% Type IV; $\mathrm{P}=0.82$ ) (Supplementary Table 3). The median decrease in bilirubin reduction after stent placement also did not differ significantly between Bismuth classes, being $2.2 \mathrm{mg} / \mathrm{dL}$ (IQR 0.5-6.6) for Type I, $3.4 \mathrm{mg} / \mathrm{dL}$ (IQR 0.8-6.0) for Type II, $2.9 \mathrm{mg} / \mathrm{dL}$ (IQR 0.8-6.0) for Type III, and $2.2 \mathrm{mg} / \mathrm{dL}$ (IQR 0.4-4.1) for Type IV (P=0.50). Further, 
Table 2 Bilirubin changes in patients by type of stent

\begin{tabular}{|c|c|c|c|c|}
\hline \multirow[t]{2}{*}{ Bilirubin by type of stent } & Total & Unilateral & Bilateral & \multirow[t]{2}{*}{ P-value } \\
\hline & $(\mathrm{N}=187)$ & $(\mathrm{N}=50)$ & $(\mathrm{N}=137)$ & \\
\hline \multicolumn{5}{|l|}{ ERCP Success } \\
\hline Yes & $187(100.0)$ & $50(100.0)$ & $137(100.0)$ & \\
\hline Bilirubin before stent placement (median [Q1, Q3]) & $5.4(2.4,13.0)$ & $4.8(2.3,7.6)$ & $6.9(2.6,13.9)$ & 0.02 \\
\hline Bilirubin 2 to 4 weeks after stent placement (median [Q1, Q3]) & $2.1(0.9,6.5)$ & $1.4(0.8,2.6)$ & $3.1(1.0,8.1)$ & 0.002 \\
\hline Decrease in bilirubin after stent placement (median [Q1, Q3]) & $2.5(0.6,5.1)$ & $2.7(0.9,4.7)$ & $2.4(0.6,5.5)$ & 0.85 \\
\hline \multicolumn{5}{|l|}{ Change in bilirubin after stent placement } \\
\hline Decrease & $158(84.5)$ & $43(86.0)$ & $115(83.9)$ & $>0.99$ \\
\hline No change & $6(3.2)$ & $1(2.0)$ & $5(3.6)$ & \\
\hline Increase & $23(12.3)$ & $6(12.0)$ & $17(12.4)$ & \\
\hline \multicolumn{5}{|c|}{ Percent of bilirubin reduction among patients who achieved clinical success } \\
\hline$\geq 75 \%$ & $45(28.5)$ & $16(37.2)$ & $29(25.2)$ & 0.06 \\
\hline$>50 \%$ to $<75 \%$ & $53(33.5)$ & $17(39.5)$ & $36(31.3)$ & \\
\hline$\leq 50 \%$ & $60(38.0)$ & $10(23.3)$ & $50(43.5)$ & \\
\hline
\end{tabular}

ERCP, endoscopic retrograde cholangiopancreatography

when patients were stratified into those with a bilirubin reduction of $\geq 75 \%,>50$ to $<75 \%$, or $\leq 50 \%, 2$ - 4 weeks following stent placement, there was no statistical difference between Bismuth classifications $(\mathrm{P}=0.72)$ (Supplementary Table 3).

\section{Adverse events}

There were significantly more adverse events in the bilateral biliary stents group compared to the unilateral stents group $(16 / 137,11.7 \%$ vs. $0 / 50,0 \% ; \mathrm{P}=0.007)$. Adverse events in the bilateral stent group included perforation $(2 / 16,12.5 \%)$, bleeding $(2 / 16,12.5 \%)$, post-ERCP pancreatitis $(11 / 16,68.8 \%)$, and cholangitis $(1 / 16,6.2 \%)$ (Table 3$)$.

The median time to occlusion was 22.5 weeks (IQR 8.0-36.0) for unilateral stents and 24.0 weeks (IQR 17.0-41.0) for bilateral stents. The use of unilateral or bilateral stents did not increase the risk of stent occlusion when adjusted for age, sex, and Bismuth classification (unadjusted $\mathrm{P}=0.71$, adjusted $\mathrm{P}=0.81$ ) (Supplementary Table 4) (Fig. 1).

Therapy for stent occlusion included repeat ERCP balloon sweeps, new stent placement or both, decided during the procedure and individualized based on the needs of the patient. Receiving bilateral stents was associated with a greater need for both balloon sweep and new stent placement $(\mathrm{P}=0.001)$, but the number of patients who had successful endotherapy was not statistically significant between the 2 groups $(\mathrm{P}=0.34)$.

\section{Survival time}

The mean follow-up time of patients from initial stent placement to last follow up or death was 32 weeks (IQR 19-52) (unilateral median 35.5, IQR 17.5-61.5, and bilateral 29.6,
IQR 19.0-48.0). During the follow-up period 122/187 (65.2\%) patients died (Supplementary Table 4). Without covariate adjustment, bilateral stents were associated with a greater risk of death compared to unilateral stents (HR 1.79, 95\%CI 1.11-2.90; $\mathrm{P}=0.02)$. This effect was maintained in the multivariable analysis, adjusting for age, sex and Bismuth classification (HR 1.78, 95\%CI 1.09-2.89; $\mathrm{P}=0.02$ ) (Table 4, Fig. 2).

\section{Discussion}

Our results show no significant difference in terms of technical success, clinical success or survival time when unilateral SEMS were compared to bilateral SEMS in patients with hilar obstruction secondary to cholangiocarcinoma. When the results were analyzed according to the Bismuth classification, unilateral stenting was equally efficacious, regardless of the location of the cholangiocarcinoma along the biliary tree. Further, inserting bilateral SEMS entailed a greater risk of adverse events and death in our study.

SEMS are widely accepted as a therapeutic option to relieve malignant strictures secondary to inoperable cholangiocarcinoma $[5,6]$. The relief of jaundice enhances quality of life in the palliative care setting and can facilitate the use of palliative chemotherapy [7]. Results remain conflicting regarding the necessity of placing unilateral versus bilateral stents, despite 2 randomized prospective studies [8-10]. One randomized controlled trial of 57 patients concluded that single stent insertion is effective and has a lower risk of complications, similar to our findings [11]. However, this study used plastic stents and did not differentiate outcomes based on the Bismuth classification, limiting its generalizability. A more recent prospective, randomized study of 133 patients by Lee et al showed similar technical success rates for bilateral and unilateral stents, 
Table 3 Adverse events

\begin{tabular}{|c|c|c|c|c|}
\hline \multirow[t]{2}{*}{ Adverse event } & Total & Unilateral & Bilateral & \multirow[t]{2}{*}{ P-value } \\
\hline & $(\mathrm{N}=187)$ & $(\mathrm{N}=50)$ & $(\mathrm{N}=137)$ & \\
\hline \multicolumn{5}{|l|}{ Immediate adverse event } \\
\hline Yes & $16(8.6)$ & $0(0.0)$ & $16(11.7)$ & 0.007 \\
\hline \multicolumn{5}{|l|}{ Types of immediate adverse event } \\
\hline Perforation & $2(12.5)$ & 0 & $2(12.5)$ & \\
\hline Bleeding & $2(12.5)$ & 0 & $2(12.5)$ & \\
\hline Pancreatitis & $11(68.8)$ & 0 & $11(68.8)$ & \\
\hline Cholangitis & $1(6.3)$ & 0 & $1(6.3)$ & \\
\hline \multicolumn{5}{|l|}{ Stent occlusion } \\
\hline Yes & $81(43.3)$ & $21(42.0)$ & $60(43.8)$ & 0.83 \\
\hline \multicolumn{5}{|l|}{ Stent occlusion by Bismuth classification } \\
\hline I & $16(19.8)$ & $6(28.6)$ & $10(16.7)$ & 0.38 \\
\hline II & $28(34.6)$ & $8(38.1)$ & $20(33.3)$ & \\
\hline III & $12(14.8)$ & $1(4.8)$ & $11(18.3)$ & \\
\hline IV & $25(30.9)$ & $6(28.6)$ & $19(31.7)$ & \\
\hline \multicolumn{5}{|l|}{ Cause of stent occlusion } \\
\hline Sludge & $8(9.9)$ & $6(28.6)$ & $2(3.3)$ & $<0.001$ \\
\hline Tumor ingrowth & $6(7.4)$ & $6(28.6)$ & $0(0.0)$ & \\
\hline Tumor overgrowth & $4(4.9)$ & $0(0.0)$ & $4(6.7)$ & \\
\hline Sludge \& tumor ingrowth & $58(71.6)$ & $9(42.9)$ & $49(81.7)$ & \\
\hline Sludge \& tumor overgrowth & $1(1.2)$ & $0(0.0)$ & $1(1.7)$ & \\
\hline Other & $4(4.9)$ & $0(0.0)$ & $4(6.7)$ & \\
\hline \multicolumn{5}{|l|}{ Therapy for stent occlusion } \\
\hline Balloon sweep only & $17(21.3)$ & $6(28.6)$ & $11(18.6)$ & $<0.001$ \\
\hline New stent placement & $11(13.8)$ & $9(42.9)$ & $2(3.4)$ & \\
\hline Balloon sweep \& new stent placement & $47(58.8)$ & $2(9.5)$ & $45(76.3)$ & \\
\hline Other & $5(6.3)$ & $4(19.0)$ & $1(1.7)$ & \\
\hline \multicolumn{5}{|l|}{ Endotherapy successful } \\
\hline Yes & $71(92.2)$ & $18(85.7)$ & $53(94.6)$ & 0.34 \\
\hline
\end{tabular}

\section{Table 4 Survival}

\begin{tabular}{|c|c|c|c|c|}
\hline \multirow[t]{2}{*}{ Survival } & Total & Unilateral & Bilateral & \multirow[t]{2}{*}{ P-value } \\
\hline & $(\mathrm{N}=187)$ & $(\mathrm{N}=50)$ & $(\mathrm{N}=137)$ & \\
\hline \multicolumn{5}{|l|}{ Death } \\
\hline Yes & $122(65.2)$ & $26(52.0)$ & $96(70.1)$ & 0.02 \\
\hline \multicolumn{5}{|c|}{ Death by Bismuth classification } \\
\hline I & $27(22.1)$ & $5(19.2)$ & $22(22.9)$ & 0.19 \\
\hline II & $41(33.6)$ & $12(46.2)$ & $29(30.2)$ & \\
\hline III & $17(13.9)$ & $5(19.2)$ & $12(12.5)$ & \\
\hline IV & $37(30.3)$ & $4(15.4)$ & $33(34.4)$ & \\
\hline
\end{tabular}

but fewer interventions were needed for patients in the bilateral stents group [12]. However, this study had a small sample size and was not sufficiently powered to detect differences.

Retrospective studies comparing bilateral and unilateral hilar stenting report high rates of technical success between $80-100 \%$ for both groups $[13,14]$. Similarly, we report a $100 \%$ technical success rate for both bilateral and unilateral stents, defined as successful passage of the wire across the stricture as intended, successful deployment of the stents, and visualized flow of contrast medium and/or bile through stents after deployment.

In terms of clinical success, the overall percentage of patients who achieved any amount of bilirubin reduction at 2-4 weeks was comparable between unilateral and bilateral drainage ( $86 \%$ vs. $82.5 \%$, respectively, $\mathrm{P}>0.99)$. Similarly, a 

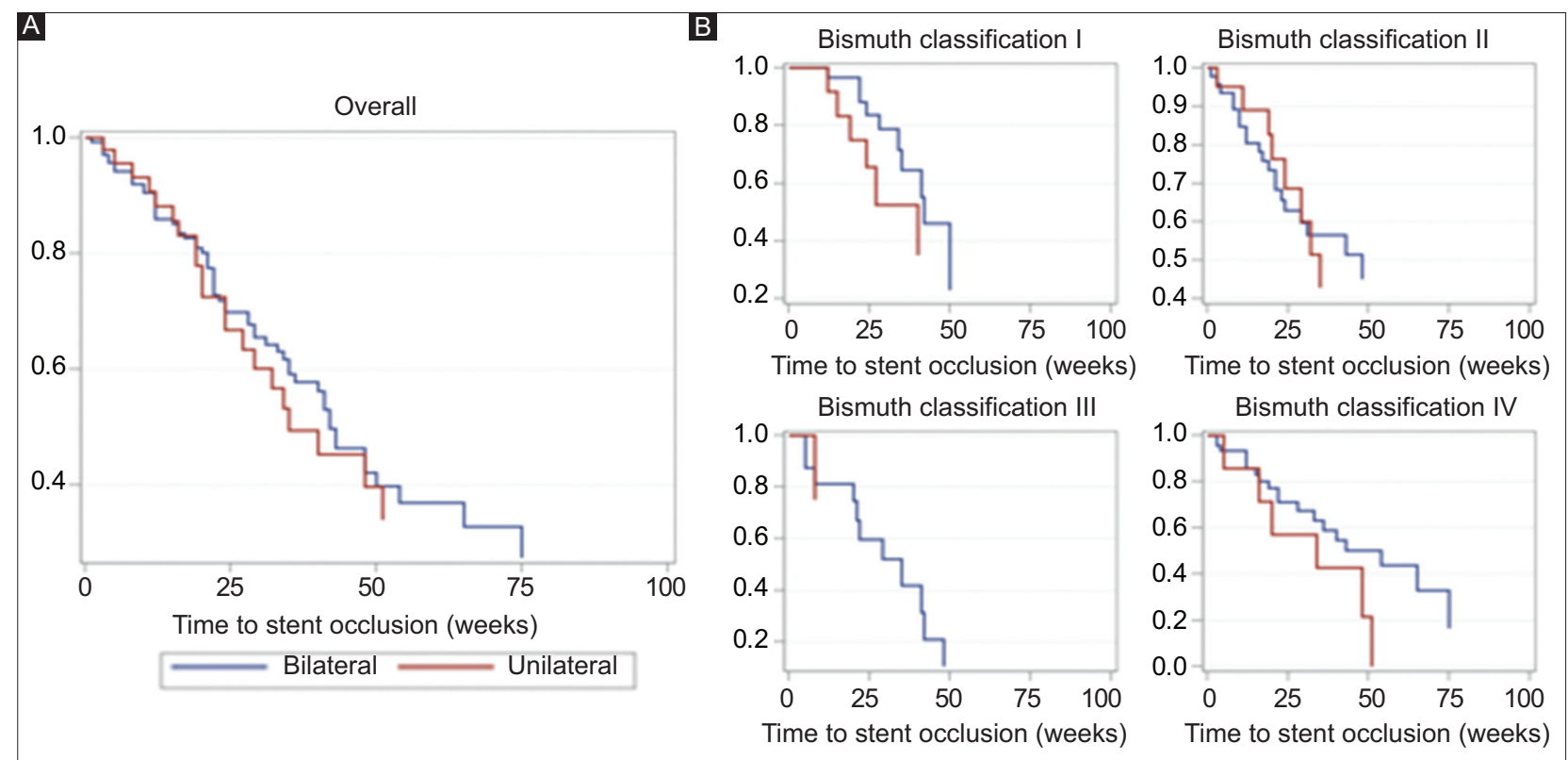

Figure 1 Cumulative stent patency overall (A) and by Bismuth classification (B), according to Kaplan-Meier analysis
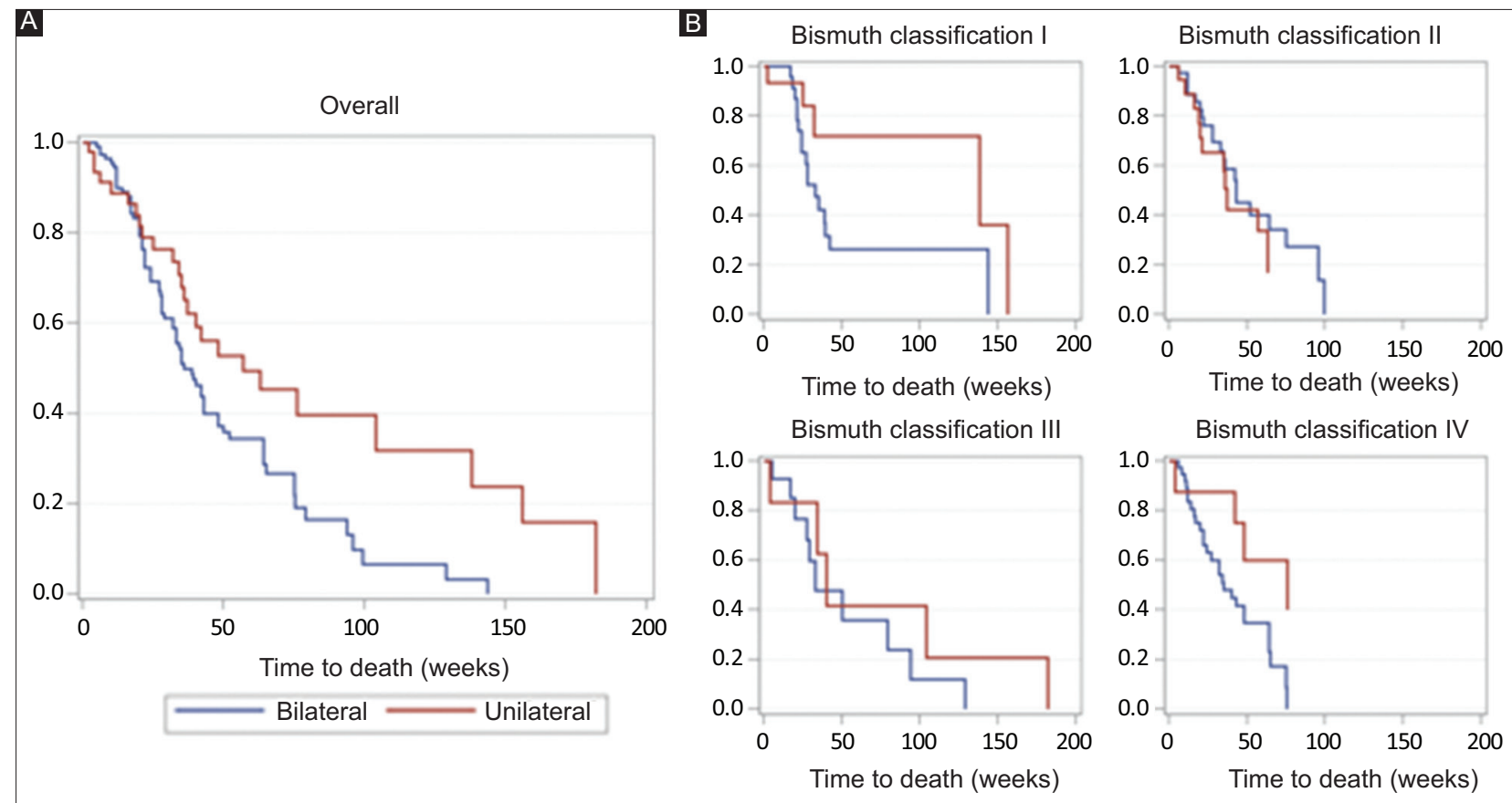

Figure 2 Cumulative time to death overall (A) and by Bismuth classification (B), according to Kaplan-Meier analysis

recent systematic review by Li et al showed no difference in the successful drainage rate (risk ratio 1.07, 95\%CI 0.97-1.18; $\mathrm{P}=0.20$ ) when comparing unilateral and bilateral drainage [8].

With regard to stratification by Bismuth classification, our data show that unilateral stents were similarly efficacious to bilateral stents, regardless of the location along the biliary tree. However, theoretically, patients with more advanced tumors (Bismuth II-IV) would benefit from bilateral stents for relief of obstruction. Vienne et al demonstrated that the main factor associated with effective drainage in more advanced tumors (Bismuth Type II-IV) was $>50 \%$ drainage of liver volume on computed tomography, which necessitated bilateral stent placement [15]. In contrast to Vienne et al, patients with Bismuth Type II-IV in our study achieved similar reductions in bilirubin, irrespectively of the number of stents placed. We hypothesize that the most important aspect in stenting a patient with a hilar malignant lesion is associated with drainage effectiveness, measured in terms of the liver volume drained. 
This adequately reduces the jaundice while helping to improve overall quality of life and patient survival. As demonstrated in our study, a single metal biliary stent in one functional liver lobe (i.e., unilateral drainage) can provide adequate palliation in the majority of patients.

Ideally, biliary stents should remain patent until the patient's demise; however, oncologic therapy often allows patients to outlive their SEMS [16]. The rate of stent occlusion $(42.0 \%$ unilateral vs. $43.8 \%$ bilateral, $\mathrm{P}=0.83$ ) and the median time to stent occlusion (22.5 weeks unilateral vs. 24 weeks bilateral) were similar in both groups studied. The literature remains conflicting in this regard; Lee et al, in their randomized prospective study, found a shorter median cumulative stent patency and areater risk of patency failure for unilateral stents, concluding that bilateral SEMS placement is favorable [12]. Naitoh et al and Liberato et al found that bilateral stenting was more effective than unilateral in terms of cumulative stent patency, while De Palma et al and Mukai et al found no significant difference between the 2 groups $[11,13,14,17]$. While Mukai et al found that the success rate of endoscopic reintervention for stent occlusion was significantly higher in those undergoing unilateral stenting rather than bilateral stenting ( $100 \%$ vs. $68 \%, \mathrm{P}=0.0272)$, our success rate was similar between these 2 groups $(85.7 \%$ vs. $88.3 \%, \mathrm{P}=0.34)$. Our data suggest that both unilateral and bilateral SEMS have high but similar rates of stent occlusion, and it is technically feasible to intervene endoscopically regardless.

Our results demonstrate that patients with hilar cholangiocarcinoma who received bilateral stents had a greater overall risk of adverse events $(16 / 137,11.7 \%$ vs. $0 / 50,0 \%$, $\mathrm{P}=0.007)$, most notably showing significantly more episodes of post-ERCP pancreatitis $(11 / 16,68 \%)$. Prior studies have reported widely varying results, but were heterogeneous as regards the type of stent used and the type of malignancy. De Palma et al found lower rates of cholangitis in patients receiving unilateral stents compared to bilateral stents $(0 \%$ vs. $7 \%$, respectively), but this study used plastic stents [11]. A retrospective study by Iwano et al concluded that unilateral drainage should be attempted before bilateral drainage, given the more serious complications in the bilateral SEMS group [18]. Other studies reported no significant differences in adverse events $[8,17]$. The reason for the greater number of episodes of pancreatitis in those receiving bilateral SEMS in our study is unclear, but the difference may have been due to the longer procedure times and more endoscopic manipulation of the ampulla during repeated cannulations when bilateral drainage is performed.

With regard to survival time, our study found that patients with bilateral stents had a greater risk of death on multivariate analysis (HR 1.78, 95\%CI 1.09-2.89; $\mathrm{P}=0.02$ ). We also demonstrated a higher rate of adverse events, particularly pancreatitis, in the bilateral stents group, which may have decreased survival. The literature again varies in this regard, but the majority of studies report no significant difference in survival time, keeping in mind that these studies used plastic stents and included malignancies other than cholangiocarcinoma $[9,11,13,17]$. Lee et al found that the median cumulative survival rate did not differ between the
2 groups, but in multivariate analyses bilateral drainage was positively associated with survival [12]. Notably, the study was not sufficiently powered to detect differences. Thus, it remains unclear if unilateral or bilateral stenting provides a mortality benefit and larger prospective studies are needed.

Our study had several limitations. First, the retrospective nature of the study inevitably raises the possibility of bias and confounding factors. We do not have the data to determine why decisions were made to place a unilateral rather than a bilateral stent. Only patients with complete medical records and follow up were included in our study. We may not have captured all patients who underwent stent placement for a hilar cholangiocarcinoma in the 8 academic centers, since patients with incomplete records were excluded from the study. Additionally, the number of patients in the unilateral stents group was smaller than that in the bilateral stents group. Given the retrospective nature of the study and the study follow-up period, there may also a bias due to underreporting of patients' adverse events.

Our study also had several strengths. This study was international and multicenter in nature. We were able to analyze all Bismuth classifications, which allowed for additional sub analyses. Also, we only examined patients who received SEMS and did not include plastic stents; this is relevant, as SEMS are now known to be superior in this setting [2,3]. Critically, our study excluded patients with malignancies other than cholangiocarcinoma; therefore, our data may only be

\section{Summary Box}

\section{What is already known:}

- Endoscopic intervention with biliary stenting is a well-established palliative therapy for patients with advanced cholangiocarcinoma with obstructive jaundice

- Controversy still exists regarding the benefits of using one or multiple metal stents (unilateral vs. bilateral stenting)

- The strategy of palliative treatment differs according to the location and/or level of the malignant biliary stricture

\section{What the new findings are:}

- Unilateral and bilateral drainage had similar technical and clinical success rates

- Bilateral stents had a higher risk of death and more adverse events.

- Our study shows that unilateral placement of self-expanding metal stents is sufficient for relief of biliary obstruction secondary to cholangiocarcinoma, even in Bismuth type IV lesions 
applicable to patients with malignant hilar strictures secondary to cholangiocarcinoma, the most common cause of hilar obstruction.

In conclusion, our study demonstrated that, in patients with hilar cholangiocarcinoma, there was no significant difference in clinical outcomes between unilateral and bilateral metal stenting, even in Type II-IV tumors. We recognize that some patients require bilateral stent placement based upon their individual needs, ductal anatomy, and overall management plan. Overall, patients undergoing bilateral stenting had higher rates of adverse events and death without improved stent patency. Therefore, our study supports the notion that unilateral stenting is a sufficient and safer first-line therapy for cholangiocarcinoma compared to bilateral stenting, irrespective of the Bismuth classification.

\section{References}

1. Nagino M, Ebata T, Yokoyama Y, et al. Evolution of surgical treatment for perihilar cholangiocarcinoma: a single-center 34-year review of 574 consecutive resections. Ann Surg 2013;258:129-140.

2. Soderlund C, Linder S. Covered metal versus plastic stents for malignant common bile duct stenosis: a prospective, randomized, controlled trial. Gastrointest Endosc 2006;63:986-995.

3. Sangchan A, Kongkasame W, Pugkhem A, Jenwitheesuk K, Mairiang P. Efficacy of metal and plastic stents in unresectable complex hilar cholangiocarcinoma: a randomized controlled trial. Gastrointest Endosc 2012;76:93-99.

4. Soares KC, Kamel I, Cosgrove DP, Herman JM, Pawlik TM. Hilar cholangiocarcinoma: diagnosis, treatment options, and management. Hepatobiliary Surg Nutr 2014;3:18-34.

5. Khan SA, Davidson BR, Goldin RD, et al; British Society of Gastroenterology. Guidelines for the diagnosis and treatment of cholangiocarcinoma: an update. Gut 2012;61:1657-1669.

6. Perdue DG, Freeman ML, DiSario JA, et al; ERCP Outcome Study ERCOST Group. Plastic versus self-expanding metallic stents for malignant hilar biliary obstruction: a prospective multicenter observational cohort study. J Clin Gastroenterol 2008;42:1040-1046.
7. Ballinger $\mathrm{AB}$, McHugh M, Catnach SM, Alstead EM, Clark ML. Symptom relief and quality of life after stenting for malignant bile duct obstruction. Gut 1994;35:467-470.

8. Li M, Wu W, Yin Z, Han G. Unilateral versus bilateral biliary drainage for malignant hilar obstruction: a systematic review and meta-analysis. Zhonghua Gan Zang Bing Za Zhi 2015;23:118-123.

9. Puli SR, Kalva N, Pamulaparthy SR, et al. Bilateral and unilateral stenting for malignant hilar obstruction: a systematic review and meta-analysis. Indian J Gastroenterol 2013;32:355-362.

10. Cassani LS, Chouhan J, Chan C, et al. Biliary decompression in perihilar cholangiocarcinoma improves survival: a single-center retrospective analysis. Dig Dis Sci 2019;64:561-569.

11. De Palma GD, Galloro G, Siciliano S, Iovino P, Catanzano C. Unilateral versus bilateral endoscopic hepatic duct drainage in patients with malignant hilar biliary obstruction: results of a prospective, randomized, and controlled study. Gastrointest Endosc 2001;53:547-553.

12. Lee $\mathrm{TH}, \mathrm{Kim} \mathrm{TH}$, Moon $\mathrm{JH}$, et al. Bilateral versus unilateral placement of metal stents for inoperable high-grade malignant hilar biliary strictures: a multicenter, prospective, randomized study (with video). Gastrointest Endosc 2017;86:817-827.

13. Liberato MJ, Canena JM. Endoscopic stenting for hilar cholangiocarcinoma: efficacy of unilateral and bilateral placement of plastic and metal stents in a retrospective review of 480 patients. BMC Gastroenterol 2012;12:103.

14. Naitoh I, Ohara H, Nakazawa T, et al. Unilateral versus bilateral endoscopic metal stenting for malignant hilar biliary obstruction. J Gastroenterol Hepatol 2009;24:552-557.

15. Vienne A, Hobeika E, Gouya H, et al. Prediction of drainage effectiveness during endoscopic stenting of malignant hilar strictures: the role of liver volume assessment. Gastrointest Endosc 2010;72:728-735.

16. Valle J, Wasan H, Palmer DH, et al; ABC-02 Trial Investigators. Cisplatin plus gemcitabine versus gemcitabine for biliary tract cancer. N Engl J Med 2010;362:1273-1281.

17. Mukai T, Yasuda I, Nakashima M, et al. Metallic stents are more efficacious than plastic stents in unresectable malignant hilar biliary strictures: a randomized controlled trial. J Hepatobiliary Pancreat Sci 2013;20:214-222.

18. Iwano H, Ryozawa S, Ishigaki N, et al. Unilateral versus bilateral drainage using self-expandable metallic stent for unresectable hilar biliary obstruction. Dig Endosc 2011;23:43-48. 


\section{Supplementary Tables}

Supplementary Table 1 Univariate and multivariate regression results

\begin{tabular}{|c|c|c|c|c|c|c|c|c|}
\hline \multicolumn{3}{|c|}{ Regression analysis } & \multicolumn{2}{|c|}{$\begin{array}{l}\text { Bilirubin before stent } \\
\text { placement }\end{array}$} & \multicolumn{2}{|c|}{$\begin{array}{c}\text { Bilirubin 2-4 weeks after stent } \\
\text { placement }\end{array}$} & \multicolumn{2}{|c|}{$\begin{array}{c}\text { Change in bilirubin after stent } \\
\text { placement }\end{array}$} \\
\hline & & & $\begin{array}{l}\text { Coefficients } \\
(95 \% \mathrm{CI})\end{array}$ & P-value & $\begin{array}{l}\text { Coefficients } \\
(95 \% \mathrm{CI})\end{array}$ & P-value & $\begin{array}{l}\text { Coefficients } \\
(95 \% \mathrm{CI})\end{array}$ & $\mathrm{P}$-value \\
\hline \multirow[t]{6}{*}{ Univariate } & Stent type & Bilateral & 3.57 (1.11 to 6.03$)$ & 0.005 & $3.14(1.05$ to 5.23$)$ & 0.003 & $0.43(-1.19$ to 2.05$)$ & 0.60 \\
\hline & Age & & 0.05 (-0.06 to 0.17$)$ & 0.36 & $0.06(-0.04$ to 0.16$)$ & 0.22 & $-0.01(-0.08$ to 0.07$)$ & 0.84 \\
\hline & Sex & Female & $0.23(-2.02$ to 2.48$)$ & 0.84 & $-0.76(-2.68$ to 1.15$)$ & 0.43 & $1.00(-0.45$ to 2.44$)$ & 0.17 \\
\hline & $\begin{array}{l}\text { Bismuth } \\
\text { classification }\end{array}$ & 2 & $0.73(-2.18$ to 3.64$)$ & 0.62 & $-0.12(-2.62$ to 2.37$)$ & 0.92 & 0.85 (-1.03 to 2.73$)$ & 0.37 \\
\hline & & 3 & $-1.06(-4.99$ to 2.87$)$ & 0.60 & $-1.23(-4.59$ to 2.14$)$ & 0.47 & $0.17(-2.37$ to 2.70$)$ & 0.90 \\
\hline & & 4 & $-1.78(-4.83$ to 1.27$)$ & 0.25 & $-1.16(-3.78$ to 1.45$)$ & 0.38 & $-0.62(-2.59$ to 1.36$)$ & 0.54 \\
\hline \multirow[t]{6}{*}{ Multivariate } & Stent type & Bilateral & 4.11 (1.61 to 6.61$)$ & 0.001 & $3.62(1.49$ to 5.75$)$ & $<0.001$ & $0.49(-1.17$ to 2.14$)$ & 0.56 \\
\hline & Age & & $0.07(-0.05$ to 0.18$)$ & 0.25 & $0.08(-0.02$ to 0.17$)$ & 0.12 & $-0.01(-0.08$ to 0.07$)$ & 0.81 \\
\hline & Sex & Female & $-0.17(-2.41$ to 2.07$)$ & 0.88 & $-1.20(-3.11$ to 0.71$)$ & 0.22 & $1.03(-0.45$ to 2.52$)$ & 0.17 \\
\hline & $\begin{array}{l}\text { Bismuth } \\
\text { classification }\end{array}$ & 2 & $0.76(-2.12$ to 3.64$)$ & 0.60 & 0.07 (-2.38 to 2.53$)$ & 0.95 & $0.69(-1.22$ to 2.60$)$ & 0.48 \\
\hline & & 3 & $-1.30(-5.15$ to 2.54$)$ & 0.50 & $-1.45(-4.73$ to 1.82$)$ & 0.38 & 0.15 (-2.40 to 2.70$)$ & 0.91 \\
\hline & & 4 & $-2.44(-5.49$ to 0.61$)$ & 0.12 & $-1.54(-4.14$ to 1.06$)$ & 0.24 & $-0.90(-2.92$ to 1.12$)$ & 0.38 \\
\hline
\end{tabular}

95\%CI, 95\% confidence interval

Supplementary Table 2 Bilirubin changes stratified by Bismuth classification in patients who received a unilateral stent

\begin{tabular}{|c|c|c|c|c|c|c|}
\hline \multirow[t]{2}{*}{ Bilirubin by Bismuth classification } & Total & I & II & III & IV & \multirow[t]{2}{*}{ P-value } \\
\hline & $(\mathrm{N}=50)$ & $(\mathrm{N}=16)$ & $(\mathrm{N}=20)$ & $(\mathrm{N}=6)$ & $(\mathrm{N}=8)$ & \\
\hline $\begin{array}{l}\text { Bilirubin before stent placement (median } \\
\text { [Q1, Q3]) }\end{array}$ & $4.8[2.3-7.6]$ & $4.9[2.6-11.3]$ & $4.7[2.3-6.6]$ & $5.0[2.3-5.5]$ & $3.8[1.9-7.2]$ & 0.95 \\
\hline $\begin{array}{l}\text { Bilirubin 2-4 weeks after stent placement } \\
\text { (median [Q1, Q3]) }\end{array}$ & $1.4[0.8-2.6]$ & $1.3[0.8-2.2]$ & $1.4[0.8-2.9]$ & $1.0[0.5-4.0]$ & $2.0[1.4-2.4]$ & 0.92 \\
\hline $\begin{array}{l}\text { Decrease in bilirubin after stent } \\
\text { placement (median [Q1, Q3]) }\end{array}$ & $2.7[0.9-4.7]$ & $3.4[0.6-5.4]$ & $2.4[1.2-4.2]$ & $2.9[0.5-4.7]$ & $2.1[0.7-5.3]$ & 0.92 \\
\hline \multicolumn{7}{|l|}{ Change in bilirubin after stent placement } \\
\hline Decrease & $43(86.0)$ & $13(81.3)$ & $18(90.0)$ & $5(83.3)$ & $7(87.5)$ & \multirow[t]{3}{*}{0.95} \\
\hline No change & $1(2.0)$ & $1(6.3)$ & $0(0.0)$ & $0(0.0)$ & $0(0.0)$ & \\
\hline Increase & $6(12.0)$ & $2(12.5)$ & $2(10.0)$ & $1(16.7)$ & $1(12.5)$ & \\
\hline \multicolumn{7}{|c|}{ Percent of bilirubin reduction among patients who achieved clinical success } \\
\hline$\geq 75 \%$ & $16(37.2)$ & $7(53.8)$ & $5(27.8)$ & $2(40.0)$ & $2(28.6)$ & \multirow[t]{3}{*}{0.62} \\
\hline$>50 \%$ to $<75 \%$ & $17(39.5)$ & $5(38.5)$ & $8(44.4)$ & $1(20.0)$ & $3(42.9)$ & \\
\hline$\leq 50 \%$ & $10(23.3)$ & $1(7.7)$ & $5(27.8)$ & $2(40.0)$ & $2(28.6)$ & \\
\hline
\end{tabular}


Supplementary Table 3 Bilirubin changes stratified by Bismuth classification in patients who received a bilateral stent

\begin{tabular}{|c|c|c|c|c|c|c|}
\hline \multirow[t]{2}{*}{ Bilirubin by Bismuth classification } & Total & I & II & III & IV & \multirow[t]{2}{*}{ P-value } \\
\hline & $(\mathrm{N}=137)$ & $(\mathrm{N}=30)$ & $(\mathrm{N}=46)$ & $(\mathrm{N}=16)$ & $(\mathrm{N}=45)$ & \\
\hline $\begin{array}{l}\text { Bilirubin before stent placement } \\
\text { (median }[\mathrm{Q} 1, \mathrm{Q} 3] \text { ) }\end{array}$ & $6.9[2.6-13.9]$ & $8.6[3.2-12.3]$ & $8.6[2.4-15.6]$ & $6.0[3.3-13.3]$ & $5.0[2.3-11.9]$ & 0.38 \\
\hline $\begin{array}{l}\text { Bilirubin 2-4 weeks after stent } \\
\text { placement (median [Q1, Q3]) }\end{array}$ & $3.1[1.0-8.1]$ & $3.9[1.5-9.2]$ & $4.2[1.1-8.5]$ & $1.8[0.7-5.3]$ & $2.5[1.0-7.8]$ & 0.42 \\
\hline $\begin{array}{l}\text { Decrease in bilirubin after stent } \\
\text { placement (median [Q1, Q3]) }\end{array}$ & $2.4[0.6-5.5]$ & $2.2[0.5-6.6]$ & $3.4[0.8-6.0]$ & $2.9[0.8-6.0]$ & $2.2[0.4-4.1]$ & 0.5 \\
\hline \multicolumn{7}{|c|}{ Change in bilirubin after stent placement } \\
\hline Decrease & $115(83.9)$ & $24(80.0)$ & $40(87.0)$ & $14(87.5)$ & $37(82.2)$ & \multirow[t]{3}{*}{0.82} \\
\hline No change & $5(3.6)$ & $2(6.7)$ & $1(2.2)$ & $1(6.3)$ & $1(2.2)$ & \\
\hline Increase & $17(12.4)$ & $4(13.3)$ & $5(10.9)$ & $1(6.3)$ & $7(15.6)$ & \\
\hline \multicolumn{7}{|c|}{ Percent of bilirubin reduction among patients who achieved clinical success } \\
\hline$\geq 75 \%$ & $29(25.2)$ & $4(16.7)$ & $12(30.0)$ & $5(35.7)$ & $8(21.6)$ & \multirow[t]{3}{*}{0.72} \\
\hline$>50 \%$ to $<75 \%$ & $36(31.3)$ & $8(33.3)$ & $10(25.0)$ & $5(35.7)$ & $13(35.1)$ & \\
\hline$\leq 50 \%$ & $50(43.5)$ & $12(50.0)$ & $18(45.0)$ & $4(28.6)$ & $16(43.2)$ & \\
\hline
\end{tabular}

Supplementary Table 4 Univariate and multivariate time to event regression results

\begin{tabular}{|c|c|c|c|c|c|c|c|c|}
\hline \multicolumn{3}{|c|}{ Time to event regression results } & \multicolumn{2}{|c|}{ Time to stent occlusion } & \multicolumn{2}{|c|}{ Time to death } & \multicolumn{2}{|c|}{$\begin{array}{l}\text { Composite time to death or } \\
\text { stent occlusion }\end{array}$} \\
\hline & & & \multirow{2}{*}{$\begin{array}{c}\begin{array}{c}\text { Hazard ratio } \\
(95 \% \mathrm{CI})\end{array} \\
(\mathrm{N}=187)\end{array}$} & \multirow[t]{2}{*}{ P-value } & $\begin{array}{l}\text { Hazard ratio } \\
(95 \% \mathrm{CI})\end{array}$ & \multirow[t]{2}{*}{ P-value } & $\begin{array}{l}\text { Hazard ratio } \\
(95 \% \mathrm{CI})\end{array}$ & \multirow[t]{2}{*}{ P-value } \\
\hline & & & & & $(\mathrm{N}=161)$ & & $(\mathrm{N}=161)$ & \\
\hline $\begin{array}{l}\text { Weeks to eve } \\
{[Q 1, \text { Q3]) }}\end{array}$ & r last follow u & nedian & $24[15-40]$ & & $32[19-52]$ & & 24 [12-39] & \\
\hline \multirow[t]{6}{*}{ Univariate } & Stent type & Bilateral & $0.91(0.55-1.50)$ & 0.71 & $1.79(1.11-2.90)$ & 0.02 & $1.05(0.71-1.57)$ & 0.80 \\
\hline & Age & & $0.98(0.96-1.01)$ & 0.13 & $1.01(0.99-1.03)$ & 0.38 & $1.00(0.98-1.02)$ & 1.00 \\
\hline & Sex & Female & $0.78(0.50-1.23)$ & 0.29 & $1.06(0.70-1.59)$ & 0.78 & $0.87(0.61-1.25)$ & 0.47 \\
\hline & $\begin{array}{l}\text { Bismuth } \\
\text { classification }\end{array}$ & II & $1.14(0.61-2.11)$ & 0.69 & $1.17(0.67-2.03)$ & 0.58 & $0.88(0.53-1.44)$ & 0.61 \\
\hline & & III & $1.53(0.72-3.24)$ & 0.27 & $1.06(0.54-2.09)$ & 0.86 & $1.06(0.57-1.98)$ & 0.85 \\
\hline & & IV & $1.26(0.67-2.37)$ & 0.48 & $1.19(0.68-2.07)$ & 0.54 & $1.22(0.74-1.99)$ & 0.44 \\
\hline \multirow[t]{6}{*}{ Multivariate } & Stent type & Bilateral & $0.94(0.57-1.56)$ & 0.81 & $1.78(1.09-2.89)$ & 0.02 & $1.04(0.69-1.57)$ & 0.84 \\
\hline & Age & & $0.98(0.96-1.01)$ & 0.19 & $1.01(0.99-1.03)$ & 0.43 & $1.00(0.98-1.02)$ & 0.77 \\
\hline & Sex & Female & $0.80(0.50-1.28)$ & 0.35 & $0.92(0.59-1.41)$ & 0.69 & $0.80(0.54-1.20)$ & 0.29 \\
\hline & $\begin{array}{l}\text { Bismuth } \\
\text { classification }\end{array}$ & II & $1.14(0.61-2.12)$ & 0.69 & $1.15(0.65-2.03)$ & 0.64 & $0.93(0.56-1.55)$ & 0.79 \\
\hline & & III & $1.50(0.70-3.18)$ & 0.29 & $1.05(0.53-2.08)$ & 0.88 & $1.06(0.57-1.98)$ & 0.86 \\
\hline & & IV & $1.31(0.69-2.51)$ & 0.41 & $1.19(0.66-2.13)$ & 0.56 & $1.34(0.79-2.26)$ & 0.28 \\
\hline
\end{tabular}

